\title{
Application of Three Levels of Evaluation Technology Based on Computer Statistics
}

\author{
Sha Ji \\ College of Sports Science, Harbin Normal University, Harbin, China \\ ji_sh_a@126.com
}

\begin{abstract}
Keywords: three-level evaluation teaching method; consistency test; mathematical statistics; comparative experiments; satisfaction degree
\end{abstract}

\begin{abstract}
. this paper was based on the application of three-level evaluation teaching method in the basketball technology teaching to conduct a comprehensive analysis of students' achievements and their own development. It used survey analysis, data statistics, the consistency test and other theoretical methods to have investigation and analysis of the results. This paper chose students of two classes in a sports college as the object of study and carried on experimental teaching through three-level evaluation teaching method, it had the statistical analysis on the students' degree of satisfaction of using three-level evaluation teaching method, and the results showed that most of the students really enjoyed this teaching method. This method promoted students' sports enthusiasm and skills, and it improved their grades from the basketball skills, at the same time the basketball technology and psychology of the students had been effectively improved.
\end{abstract}

\section{Introduction}

At present, the contemporary education evaluation is a field that the new education reform pays more attention to its research[1,2]. In the teaching process of our country's modern basketball technology, the education of sports teaching is an important indicator to realize the teaching mode and teaching achievements. Especially it focuses on the current phenomenon that the evaluation results mutually disjoint with the teaching activities in the course of basketball teaching, the usage of evaluation methods and performance scoring methods that have competitive technology[3,4].It can greatly enhance the interaction between teachers and students, and it also improves the rationality of the evaluation results[5]. At the same time, reasonable evaluation method fully demonstrates the students' personality and spirit of innovation and realizes the improvement of sports teaching quality. In this paper, three-level evaluation teaching method made students as the main body, the teaching process was combined with students' performance evaluations, and in this way it could have systematic, comprehensive and objective evaluation of the basketball technology course in the whole teaching process[6]. Therefore, it used the method of experimental research to have analysis on the actual results of three-level evaluation teaching method in the basketball teaching.

\section{The research objects and methods}

TABLE I. DATA ANALYSIS ON THE OBJECTS OF QUESTIONNAIRE INVESTIGATION

\begin{tabular}{|c|l|l|l|l|}
\hline & \multicolumn{1}{|c|}{$\begin{array}{c}\text { Total number of } \\
\text { questionnaires }\end{array}$} & $\begin{array}{c}\text { The number of returned } \\
\text { questionnaires }\end{array}$ & $\begin{array}{c}\text { The number of effective } \\
\text { questionnaires }\end{array}$ & $\begin{array}{c}\text { The effective } \\
\text { return rate }\end{array}$ \\
\hline Investigation of teachers & 50 & 46 & 45 & $97.22 \%$ \\
\hline Investigation of students & 200 & 180 & 176 & $93.00 \%$ \\
\hline
\end{tabular}

This paper was mainly aimed at the students and teachers of sports colleges to carry on the questionnaire survey, and it mainly understood the university's analysis of the present situation of sports teaching and the analysis on the impact factor of university education activities. The effective return rate of questionnaire investigation reached more than $90 \%$, and it can be seen in Table 1 .

The reliability is used to test the degree of reliability of the questionnaires, and it is usually expressed with the value of the reliability coefficient, the formula of the reliability coefficient is[7]:

$$
R_{x x}=\frac{S T 2}{S_{x}^{2}}
$$


ST2 is the true variation value, and $\mathrm{Sx} 2$ is the actual variation value. The results can be calculated by using the SPSS software[8].

$$
\alpha=\left(\frac{k}{k-1}\right)\left(1-\frac{\sum S i 2}{S \times 2}\right)
$$

It can use $\alpha$ coefficient to test internal consistency, the formula is[9]:

$$
\alpha=\left(\frac{k}{k-1}\right)\left(1-\frac{\sum S i 2}{S x 2}\right)
$$

$\mathrm{K}$ : the total score of questions in the questionnaire; Si2: the variance of a question's score; Sx2: the variance of all the research scores in the questionnaire.

The content of the questionnaire survey was based on the analysis and understanding of the person in charge of the universities and the experts to have the formulation. And it took the analysis of reliability and validity of the questionnaire, unrelated issues were eliminated. The results of the test were that the corresponding coefficient of reliability test was greater than 0.8 , and when $\mathrm{P}$ was less than 0.01 , they were in the highly significant situation[10]. This fully expresses that the credibility of the questionnaire is relatively high, and therefore it is more appropriate to have research.

\section{Test method and the test content}

The two classes in the sports colleges were set as the experimental class A and comparative class $\mathrm{B}$, and each class had 50 boy students[11]. Through survey statistics of the medical examination, it was known that the distribution of two groups of students' physical quality was similar, and through the $\mathrm{T}$ test they had no significant difference, so they could be used as test objects. Under guidance of same physical education teachers, there had the same teaching content of basketball technology teaching[12]. The teaching achievement was audited through three-level evaluation teaching method.

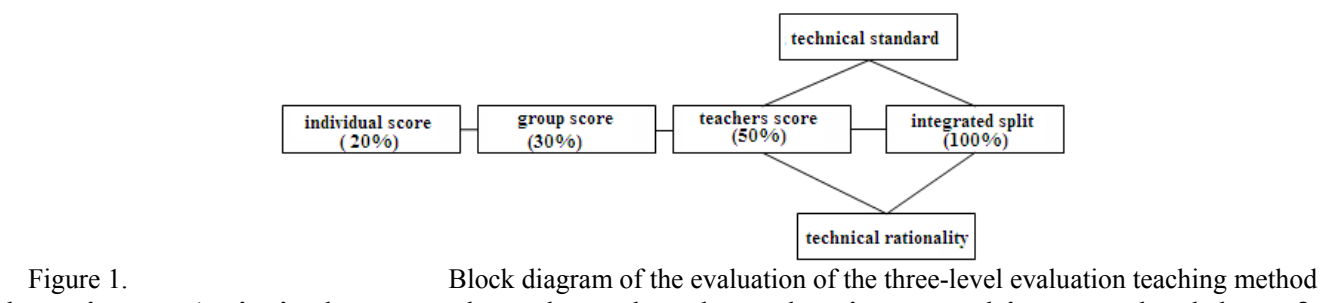

From the Figure 1, it is known that three-level evaluation teaching method has four steps to evaluate achievement of basketball technology teaching. Firstly the students have self-evaluation, and the results account for $20 \%$ of total score[13]. Then the students in the same class have mutualevaluation and obtain the average score, it accounts for $30 \%$ of the final result. Basketball teacher gives the remaining $50 \%$ of the score according to the actual situation. The teacher is through the technology standardization and the rationality of the basketball technology learning to add the scores of three-level evaluation, and the result is the total score of the student's basketball technology course.

\section{Results and analysis}

TABLE II. STATISTICAL TABLE OF THE STUDENTS' DEGREE OF SATISFACTION IN TWO CLASSES

\begin{tabular}{|c|l|l|l|l|l|l|l|l|}
\hline Category & $\begin{array}{c}\text { The total } \\
\text { number of } \\
\text { students }\end{array}$ & $\begin{array}{c}\text { Degree of } \\
\text { effort }\end{array}$ & \% & $\begin{array}{c}\text { Degree of } \\
\text { progress }\end{array}$ & \% & PE Ability & $\begin{array}{c}\text { Degree of } \\
\text { satisfaction }\end{array}$ \\
\hline Experimental class $\boldsymbol{A}$ & 50 & 46 & 92 & 38 & 76 & 44 & 88 & 42 \\
\hline Comparative class B & 50 & 38 & 76 & 36 & 72 & 40 & 84 \\
\hline
\end{tabular}

The results of the two classes' performance of basketball teaching that obtained by using the three-level evaluation teaching method had the survey analysis. The students in two classes were basically satisfied with the results. The results are shown in Table 2. 


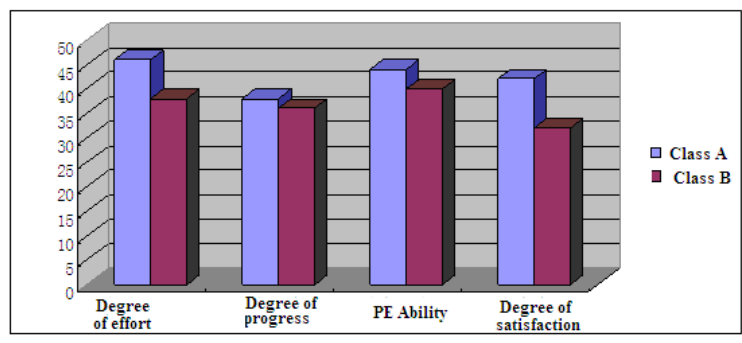

Figure 2.

Comparison chart of students' degree of satisfaction in two classes

From Table 2 and Figure 2 we can know that the three-level evaluation teaching method is used to evaluate the performance of the basketball technology teaching course, in this way the students can obviously improve the learning enthusiasm, and sports ability and basketball technology also have improvement. The degree of effort, speed of progress of basketball technology, physical ability and other aspects have obvious improvement. Especially in class A the degree of satisfaction of threelevel evaluation teaching method reaches $84 \%$. This suggests that students generally use this teaching method to improve their academic performance and other aspects.

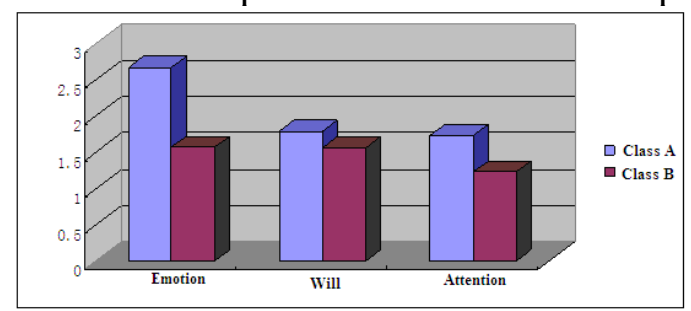

Figure 3.

Comparison chart of students' psychological factors of using the three-level evaluation teaching method

Table III. Statistical table of the students' psychological factors

\begin{tabular}{|c|l|l|l|l|l|l|}
\hline Category & \multicolumn{1}{|c|}{$\begin{array}{c}\text { Total } \\
\text { number }\end{array}$} & \multicolumn{1}{|c|}{ Emotion } & \multicolumn{1}{c|}{ Attention } & \multicolumn{1}{c|}{ Will } & \multicolumn{1}{c|}{$\begin{array}{c}\text { Integrated } \\
\text { parameters }\end{array}$} & \multicolumn{1}{c|}{$\begin{array}{l}\text { Upper } \\
\text { level }\end{array}$} \\
\hline Experimental class A & 50 & $2.67 \pm 0.08$ & $1.79 \pm 0.06$ & $1.74 \pm 0.08$ & $20.7 \pm 0.06$ & $\begin{array}{l}\text { Medium } \\
\text { level }\end{array}$ \\
\hline Comparative class B & 50 & $1.57 \pm 0.09$ & $1.56 \pm 0.11$ & $1.23 \pm 0.03$ & $1.61 \pm 0.07$ & $<0.01$ \\
\hline & $\mathrm{P}$ & $<0.01$ & $<0.01$ & $<0.01$ & & \\
\hline
\end{tabular}

Table IV. Comparison table of the teaching performance of using the three-level evaluation teaching method

\begin{tabular}{|c|l|l|l|l|l|}
\hline Category & \multicolumn{1}{|c|}{ Total number } & $\begin{array}{c}\text { The total score of } \\
\text { quality }\end{array}$ & $\begin{array}{c}\text { The total score of } \\
\text { technology }\end{array}$ & $\begin{array}{c}\text { The total score of } \\
\text { tactics } \\
\text { identifying the images }\end{array}$ \\
\hline Experimental class $\boldsymbol{A}$ & 50 & $6.95 \pm 0.89$ & $7.15 \pm 0.86$ & $7.04 \pm 0.78$ \\
\hline Comparative class $\boldsymbol{B}$ & 50 & $6.57 \pm 0.90$ & $6.92 \pm 0.86$ & $6.73 \pm 0.93$ \\
\hline & $\mathrm{P}$ & $>0.05$ & $<0.01$ & $<0.01$ \\
\hline
\end{tabular}

From Table 3 and Figure 3 we can know that the usage of three-level evaluation teaching method can adjust students' emotion, attention, and individual will and other psychological aspects in the process of basketball technology teaching. The result shows that the students' psychological development is gradually moving toward the healthy development of the road, and it has great improvement in interpersonal communication and cooperation and other aspects. For example, the students' control of their own emotion in class A is $2.67 \%$. They are obviously able to control their own emotion and prevent the conflicts between the classmates[14-16]. This tendency makes the students' interaction more rational, it also makes the interaction between students and teachers more actively, at the same time it promotes the teaching and learning of basketball technology courses.

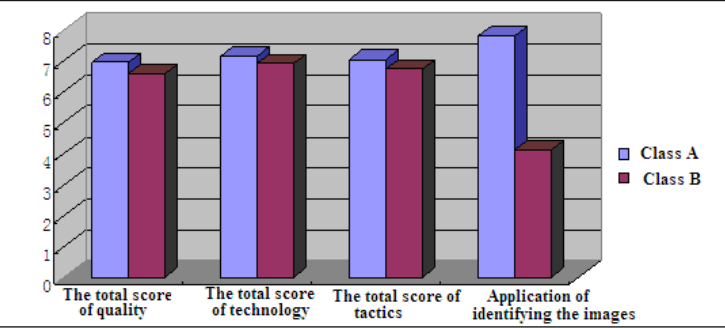

Comparison table of the teaching performance of using the three-level evaluation teaching method 
From Table 4 and Figure 4 we can know that the performance of experimental class A obtained in the basketball technology courses is generally higher than the comparative class. In the application of basketball technology and the tactics, $\mathrm{p}<0.01$ shows that the experimental class has obvious advantages.

The result shows that through the three-level evaluation teaching method the students' results of the experimental group have obvious improvement. This shows that the three-level evaluation teaching method has certain incentive effect on the students, and the method makes students actively learn the basketball technology, at the same time it lets the students' psychology gradually form the right road of growth.

\section{Conclusion}

The cultivation of the students' ability of playing basketball is closely related to the concept of basketball sports education, and it has to meet the society's requirement of quality education, skill education and the comprehensive development. So it should strengthen the cultivation of the students' ability of playing basketball, and make full use of the teaching technology of three-level evaluation teaching method. The enhancement of the cultivation of students' basketball sports ability, we must firstly strengthen the requirements for teachers' teaching, and it is only to constantly strengthen the construction of teachers, the teachers' quality can obtain the improvement to ensure efficient education quality, and then it can effectively complete the teaching task. And the teacher should continuously follow up modern information technology teaching mode to innovate the teaching in the classroom and to give exercise and training to the students' creative thinking. The teacher also should give full play to the personal charm to integrate into the students, build good relationship with students, carry on scientific means to guide students to have physical training, make classroom atmosphere more active, and stimulate students' interest and initiative in basketball teaching.

The second is to strengthen the optimal selection and plan of the teaching content and realize the optimized configuration. It not only has to ensure that the courses are good and suitable for use in the teaching, but also should make basketball sports bring great benefit to students' physical and mental health. In today's society when people pay attention to the pursuit of spiritual enjoyment, at the same time they have to focus on the mental education, and in this way it can make the students get some exercise and enjoy the art style and great charm of the basketball sports teaching. This method realizes the skills education, and at the same time it also can improve the quality education.

Finally it has to strengthen the continuous innovation of basketball sports teaching methods, it should pay attention to integration of science and knowledge, and enhance comprehensive cultivation of physiological knowledge and psychological knowledge. The teachers should do more heuristic education and use the three-level evaluation teaching method to promote interaction with students, the teachers also have to constantly strengthen exercise and cultivation of students' innovation consciousness, and they can continue to stimulate the students' interest in basketball sports to make the students learn and take the exercise in the entertainment, and at the same time the students can have entertainment in the learning and training. At the same time the modes and methods of basketball sports teaching should give attention to each student's individual needs and development, and they have to teach students in accordance with their aptitude.

\section{Acknowledgments}

The authors were appreciated for the support from the education projects for Humanities and social sciences of Heilongjiang Provincial Department with the program name Research on Current Situation and Talent Training Mode of Basketball Players in Heilongjiang Province Colleges and Universities from the 14th CUBA Qualifying Games and the Program number 12522144.

\section{References}

[1] Ma Guixia. Research of assessment content and design of aerobics special club course [J].Journal of Beijing basketball sports university, 2005, (11):39-42 
[2] Wang Lihua. Set up the concept of "course" and step by step promote the new curriculum [J].Journal of Guizhou education institute report, 2009(5):71-73

[3] Sun Han. Scan the change of the basketball sports teachers' function from the concept of "course" [J].Journal of Beijing basketball sports university, 2009(09):55-58

[4] Shan Fengjun, Hao Gangling. Practice and study of big course of the basketball sports [J]. Journal of Neijiang science and technology, 2008(4):91-95

[5] Wang Sen. Build a large curriculum system to create the modern talent education platform [J]. 2004(09):17-20

[6] Zhou Xuerong, Tan Mingyi. Research of constructing the major curriculum system of college basketball sports [J]. Journal of Beijing basketball sports university, 2003(6):26-28

[7] Tian Shenghui, Tang Juxiang. Orientation of kindergarten curriculum under the vision of concept of big course [J].Journal of Huaihua institute, 2006(7):86-89

[8] Wu Jun. Study on the reform of university basketball teaching [J].Journal of movement, 2010(01):64-67

[9] Zhang Junhong. Comparative analysis of university basketball teaching methods [J].Extracurricular education in China, 2009(6):103-106

[10] Jin Dongtao, Zhao Xiaokun. Exploration of the teaching method of university basketball elective course [J].Extracurricular education in China, 2009(8):52-55

[11] Ling Min. Thinking of the concept of modern basketball teaching in the university [J].Journal of basketball sports teachers, 2006(3):75-78

[12] Hu Xueming, Xing Shuangtao. The reform and analysis of teaching and evaluation concept of the basketball technology teaching in the basketball sports colleges under the new situation [J].Journal of Henan institute of education (natural science edition), 2006(3):37-40

[13] Li Xia. The usage and discussion of the concept of "three live" in the basketball classes [J]. Guide of Sci-tech Magazine, 2008(20):49-51

[14] $\mathrm{Hu}$ Bendong. Ideas of teaching reform of university basketball option class under the concept of the new outline [J]. Journal of Jining college, 2008(3):98-102

[15] Ji Qing. Research of university basketball teaching under the concept of "Happy basketball sports" [J].Journal of commercial culture (academic edition), 2010(8):63-66

[16] Zhao XinYu. Research of the penetration of team spirit concept in the high school basketball teaching [J].Young writer, 2009(20):86-89 